\title{
Socio-economic consequences of cattle predation by the Endangered Persian leopard Panthera pardus saxicolor in a Caucasian conflict hotspot, northern Iran
}

\author{
Sima Babrgir, Mohammad S. Farhadinia and Ehsan M. Moqanaki
}

\begin{abstract}
In the Caucasus the Endangered Persian leopard Panthera pardus saxicolor has been persecuted to the verge of extinction, primarily as a result of conflict with people over livestock predation. The socio-economic factors that influence this interaction have received little attention and the attitudes of local people towards leopards remain unknown. Here we assess the extent of cattle predation by leopards and how this influences people's attitudes towards leopards among village residents around the Dorfak NoHunting Area, a priority reserve in the Iranian Caucasus. In a survey of 66 households, $48 \%$ of interviewees reported losing cattle to leopards during 2009-2011. A mean of c. 0.7 head of cattle per interviewed household was reportedly killed by leopards over the 3-year survey period. Cattle predation peaked during warm seasons, when most family members were busy with rice farming-related activities, thus leaving their cattle grazing unguarded in the forest. Regardless of the intensity of cattle predation or socioeconomic status, $80 \%$ of respondents perceived leopards as a pest, with $45 \%$ of interviewees expressing support for either licensed hunting or culling of the Dorfak leopards. We recommend that the Iranian government considers the financial consequences of livestock loss for poor rural communities across the leopard's range. In addition, a combination of different livestock husbandry practices, with the direct involvement of local residents, is essential to ensure the long-term survival of the regional leopard population of the Caucasus.
\end{abstract}

Keywords Attitudes, Caucasus, compensation, conflict mitigation, conservation, human-carnivore conflict, leopard

To view supplementary material for this article, please visit http://dx.doi.org/10.1017/So030605315000903

\footnotetext{
Sima Babrgir (Corresponding author), Mohammad S. Farhadinia (Corresponding author) and EHSAN M. MoQANAKI Iranian Cheetah Society, PO Box 14155-8549, Tehran, Iran

E-mail babrgir@gmail.com; msfarhadinia@wildlife.ir

${ }^{*}$ Also at: Department of Zoology, Wildlife Conservation Research Unit, University of Oxford, Abingdon, UK

Received 6 January 2015. Revision requested 21 May 2015

Accepted 24 July 2015. First published online 9 December 2015.
}

\section{Introduction}

Wild carnivores have been persecuted as pests throughout history, either in direct retaliation for livestock predation or through precautionary, governmentsponsored attempts at extermination (Thirgood et al., 2005; Loveridge et al., 2010; Rigg et al., 2011). The underlying factors leading to the persecution of large predators are complex and are also linked to local perceptions and cultural values (Zimmermann et al., 2005; Treves \& Bruskotter, 2014). In rural communities where livestock has high economic and social importance and is an important source of income, livestock losses affect local attitudes towards, and acceptance of, large carnivores (Zimmermann et al., 2005; Dar et al., 2009; Amador-Alcalá et al., 2013). Understanding the factors that contribute to the complexity of conflict issues is crucial if conservationists are to facilitate the development of appropriate mitigation strategies (Dickman et al., 2013).

The Persian leopard Panthera pardus saxicolor, categorized as Endangered on the IUCN Red List (Khorozyan, 2008), is one of the least-studied subspecies of leopard, inhabiting a wide range of montane habitats in West and Central Asia. Iran is a stronghold for leopards in the region, and reportedly acts as a source for small and highly threatened leopard subpopulations in the Caucasus Ecoregion (Khorozyan, 2008). Wild ungulate populations have been depleted in the Iranian Caucasus, and people and their livestock now dominate the landscape (Moqanaki et al., 2013), making leopard-livestock conflict inevitable. Despite this conflict, these interactions have received very little attention and there has been no assessment of public attitudes towards the Persian leopard. In particular, such studies are needed in protected areas as inadequate understanding of the ecological and social aspects of conflict may hinder the success of any management practices (Loveridge et al., 2010).

Post-revolution Iran, with a human population that almost doubled between 1980 and 2000, has experienced a profound socio-demographic change from a primarily agricultural nation to an urbanized, developing country. This development has widened the urban-rural gap, making rural communities more vulnerable to the country's relatively poor economic performance (Mojtahed \& Esfahani, 1989; Mazarei, 1996). Those living within such fragile local 


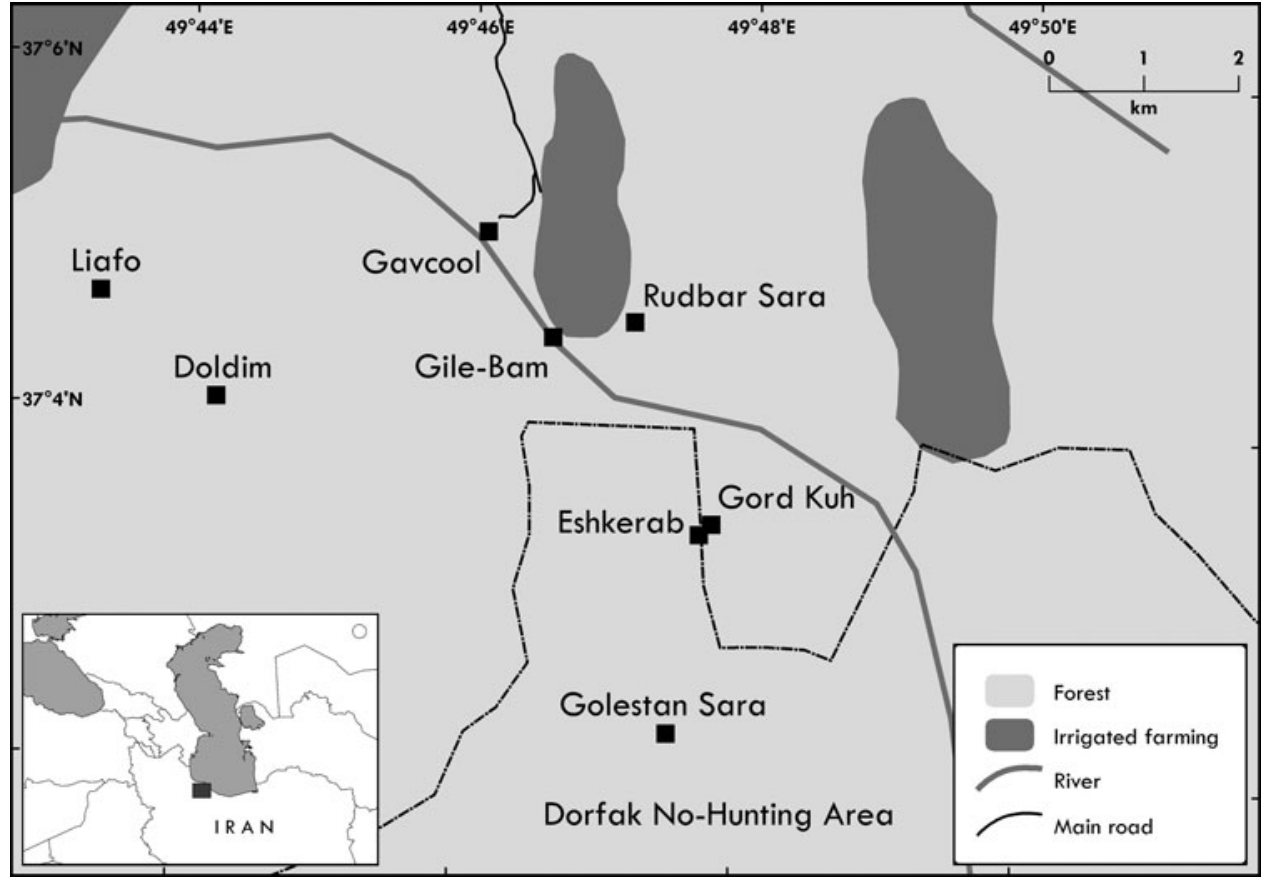

FIG. 1 Villages close to the northern perimeter of the Dorfak No-Hunting Area, where a questionnaire survey was conducted to obtain data on leopard-cattle conflict and local people's attitudes towards the Persian leopard Panthera pardus saxicolor. economies rarely tolerate the financial risk associated with coexistence with large carnivores, and rural residents often take lethal measures against any conflict species (Hemson et al., 2009; Amador-Alcalá et al., 2013).

Our goal in this study was to investigate the extent of cattle predation by Persian leopards and to assess the intensity of conflict between rural residents and leopards in a conflict hotspot in the Iranian Caucasus. We aimed to determine the degree of tolerance towards leopards where cattle losses occur, and how predation intensity shapes people's perceptions and attitudes to interventions related to leopard conservation. We anticipated that a high intensity of cattle predation by leopards would be the main cause of any negative attitudes towards and low tolerance of leopards. Our results are intended to contribute to a better understanding of the socio-economic factors involved in livestock predation by the Persian leopard, and to provide insights for conflict management in the human-dominated habitats of the Caucasus Ecoregion.

\section{Study area}

Located in the northern foothills of the Alborz Mountains, along the southern Caspian coast (Fig. 1), the Dorfak No-Hunting Area is a priority leopard reserve for the Caucasus Ecoregion. With an area of c. $379 \mathrm{~km}^{2}$, the Area has a significant representation of Hyrcanian mixed forests (90\% cover). The remainder of the reserve and surrounding area is mainly dominated by agricultural lands and grazing pastures. There are an estimated 3,063 people (in 796 households) living in 61 villages inside and along the periphery of the Area. By the early 2000 s c. $40 \%$ of villages formerly located within the Area were relocated outside the reserve as part of a national plan to protect Iran's remnant forests against overgrazing by livestock.

\section{Methods}

\section{Selection of villages}

A reconnaissance questionnaire survey of the local wildlife authority and wardens of Dorfak No-Hunting Area revealed that people living along the northern perimeter of the reserve (Fig. 1) routinely complain about losing cattle to leopards. We therefore prioritized for investigation the eight villages in this area that had the highest number of cattle-loss claims during 2009-2011 (Fig. 1). The majority of rural residents were farmers and most families possessed poultry and cattle. Cattle are considered a source of wealth for these rural communities. Male cattle are raised for sale as meat whereas females are usually kept for dairy production and breeding. Animal husbandry practices are generally similar throughout the eight villages: cattle are driven up to $5 \mathrm{~km}$ from the village to graze in the forest during the warmer season (March-September), returning on their own each night to corrals within the village. These corrals also serve as permanent shelters during the colder season (October-February), when the cattle are fed on hay or rice foliage collected during the summer.

\section{Questionnaire survey}

During February-March 2012 we conducted a semistructured questionnaire survey (Supplementary Material 1) 
to obtain data on leopard-cattle conflict and the perceptions and attitudes of local people towards the leopard. Prior to data collection all team members received training based on guidelines for interview-based surveys developed from similar studies (e.g. Zimmermann et al., 2005; Majic \& Bath, 2010). We tried to interview primarily the head or spouse of randomly-selected households, but other family members often participated. We were therefore able to cross-check and validate the interview data and record a collective response. We conducted unstructured interviews in a friendly environment, to gain the trust of interviewees and to avoid bias. We evaluated respondents' ability to identify the leopard by showing them photographs of different predators.

The questionnaire had four sections: (1) demographic and socio-economic characteristics of respondent, and the number and insurance status of the household's cattle; (2) experience of cattle being predated by leopards; (3) an exploration of the respondent's knowledge about leopard ecology (as perception of a species can considerably influence human-animal interactions; Lescureux et al., 2011; Dickman et al., 2013); (4) attitudes towards the leopard and leopard conservation. To assess the intensity of damage, past experiences of leopard attacks on cattle were obtained (date, location, and frequency of losses) based on what the respondents remembered from the previous 3 years (20092011). We investigated local people's attitudes using a series of statements regarding the leopard and its conservation, and responses were recorded on a three-point scale (agree, unsure and disagree).

\section{Statistical analysis}

We used descriptive statistics for all demographic and attitudinal questions. We combined the answers to all attitude statements into a single additive score (Walpole \& Goodwin, 2001; Zimmermann et al., 2005). We coded answers to each question from zero to two (negative, unsure, positive), and summed the codes to create a combined score of o-14, with higher scores indicating a more positive overall attitude to leopards. Similarly, we calculated an overall 'conservation attitude' score of $0-12$ from six statements (Supplementary Material 1).

We used multiple linear regression to examine the importance of age, gender and percentage of cattle loss as predictors of attitude. We used Pearson product-moment correlation analysis to explore associations between the combined score and the number of cattle owned by respondents and predated by leopards. We conducted all analyses in $R$ v. 3.2.2 (R Development Core Team, 2015).

We used Correspondence Analysis (Benzecri, 1992) to assess the impact of predation patterns on the attitudes of respondents. Correspondence Analysis explores correspondence between variables in order to explain the most variance in the model in the least number of dimensions (Doey \& Kurta, 2011). We implemented Correspondence Analysis with PAST v. $2.17 \mathrm{C}$ (Hammer et al., 2001), which uses symmetric scaling (Benzecri scaling). We prepared the data matrix with respondents as rows and their attitude towards leopards as variables/ columns. We grouped respondents by intensity of conflict (each defined as a convex hull), which we defined as the percentage of the household's cattle killed by leopards in the preceding year (convex hull).

\section{Results}

Respondent demographics and cattle holding We interviewed a total of 66 households (corresponding to $25.1 \%$ of the total number of households in the surveyed villages) as follows: Gavcool: 7 (11.7\% of the total number of households); Gile-Bam: 9 (26.5\%); Eshkerab: 5 (22.7\%); Rudbar Sara: 5 (29.4\%); Doldim: 9 (5.4\%); Liafo: 24 (47.1\%); Golestan Sara: 3 (17.6\%); Gord Kuh: 4 (25.0\%). The respondents were aged $18-70$ years (mean $44.6 \pm$ SE 1.7), and gender ratio was almost equal (34 male vs 32 female). Rice farming was the main occupation of the respondents. Cattle are regarded as assets in their own right, but $94 \%$ of the interviewees also herded cattle to meet the dairy needs of the family. With the exception of one respondent who owned an exceptionally large herd of cattle $(n=48)$, livestock consisted of small to medium herds of cattle (1-25, mean 7.0 \pm SE 0.9$)$.

Cattle predation by leopards Overall, predation by leopards was reportedly the major cause $(57.6 \%)$ of cattle loss for the surveyed households, followed by disease $(24.7 \%)$, theft $(8.2 \%)$, birth-related problems $(8.2 \%)$, and unknown causes (1.2\%). Forty-eight percent of respondents suffered loss of cattle to leopards during 2009-2011. Cattle predation peaked during the warm season (i.e. March-September; $72 \%$ ), and in total 49 head of cattle were reported killed by leopards. A mean of $0.7 \pm$ SE 0.1 cattle per surveyed household were killed by leopards during 2009-2011, and $27(55.1 \%)$ of the reported losses occurred in 2011. None of the respondents had any form of livestock insurance for their cattle and $53.0 \%$ of them stated they were not aware of any compensation schemes. Only $67 \%$ of respondents expressed willingness to receive financial compensation for cattle killed by leopards.

Knowledge and perceptions of leopards The majority of respondents correctly identified leopard pictures and signs of leopard predation. Leopards were well-known by $69.2 \%$ of the interviewed residents although only $15.4 \%$ of 
respondents claimed to have encountered the species in the wild. Just over half $(51.5 \%)$ of respondents believed that a large population of leopards lives in the nearby Dorfak No-Hunting Area, with a minimum population size of 10 , and $56.1 \%$ maintained that the number of leopards has recently increased in the Area because 'the Department of Environment has released domesticated leopards into the forest' and 'it is why the animal tends to approach our villages and cattle'. The reproductive rate of leopards was also considered to be high and even 'comparable to that of dogs' (2-4 cubs on a yearly basis) according to $63.6 \%$ of respondents. Sixty-six percent of interviewees reported cattle to be the main food of leopards in the area, expressing that 'nothing is left for leopards to eat except [wild] pigs, but hunting cattle is much easier for them'. They believed that in spring and during the growth of leaves, the number of leopards increases and they attack people's cattle more frequently'. Respondents considered the leopard to be a 'bloodthirsty predator that attacks cattle's necks and just drinks their blood'. Only three respondents (4.5\%) mentioned rumours of leopards attacking humans, and all referred to a single incident that allegedly occurred in summer 2011. Respondents also mentioned that 'there is no way to save cattle against leopards; even guarding dogs are ineffective as leopards eat dogs as well'.

Conservation attitudes Combined values for leopard attitude scores ranged from 4 (negative) to 14 (positive), with a mean score of $7.5 \pm$ SE 0.2 per person, suggesting an overall neutral attitude towards leopards. Combined values for the conservation attitude scores were o-10 (mean 6.4 \pm SE 0.2 ). Most respondents (80\%) said that leopards cause damage to cattle, and $36 \%$ perceived them as a threat to people (Table 1). Forty-eight percent of respondents believed that it is not necessary for leopard conservation to have leopards in Dorfak No-Hunting Area as the predator exists in other parts of Iran. Forty-five percent of respondents agreed that the hunting of leopards should be allowed within a specific season as an effective management tool (Table 1). During 2009-2011, only one verifiable record of leopard poaching was obtained (an adult male). A juvenile female was also found dead in 2011 in a snare trap installed for wild pigs Sus scrofa near a rice farm.

Factors influencing attitudes towards leopards There was no evidence that the number of cattle owned and the number of loss claims were related $(r=0.19, \mathrm{df}=63$, $\mathrm{P}=0.12$ ). Nor was there evidence that the composite leopard attitude and conservation metric was related to the intensity of cattle predation by leopards $(r=0.09, \mathrm{df}=63$, $\mathrm{P}=0.48$ and $r=0.05, \quad \mathrm{df}=63, \mathrm{P}=0.69, \quad$ respectively;
TABLE 1 Percentage of responses in agreement with statements about the Persian leopard Panthera pardus saxicolor and leopard conservation in the Dorfak No-Hunting Area, Iran (see Supplementary Material 1 for details)

Agreement (\%)

\section{Attitudes}

It is important to maintain leopard population $\quad 21$ in Iran for future generations.

There is no need to have leopards in this area 48

because they already exist in other parts of Iran.

Leopards have an important role in the

ecosystem.

Leopards, like other beings, have the right to 62

exist in Iran.

Leopards would increase tourism in the region. 15

Leopards cause a lot of damage to livestock. $\quad 80$

Leopards are a threat to people. 36

\section{Conservation}

Leopards deserve protection in Iran. 27

Leopards should be allowed to be hunted in a $\quad 45$

specific hunting season in Dorfak No-Hunting Area.

A leopard that comes close to human residences 32 should be killed.

A leopard that frequently preys on livestock $\quad 44$

should be killed.

Local people should receive compensation for $\quad 67$

the damage that leopards cause to their

livestock.

If leopards attack livestock as a result of lack of 27

proper husbandry, the state is not obligated to

compensate.

Fig. 2a). We found no relationship between the combined attitude scores and interviewee age classes $\left(F_{3,61}=1.909\right.$, $\mathrm{P}=0.14$ and $F_{3,61}=0.175, \mathrm{P}=0.91$, respectively; Fig. $2 \mathrm{~b}$ ). However, men tended to show higher mean scores (more positive attitudes) than women $\left(F_{1,61}=4.87, \mathrm{P}=0.031\right.$; Fig. 2c). The first three axes of the Correspondence Analysis model explained $72.1 \%$ of the total variance (i.e. the intensity of leopard predation explains $72.1 \%$ of the variance in the patterns of respondents' attitudes towards the leopard; Table 2). The four overlapping convex hulls that denote the different levels of cattle predation (Fig. 3 ) suggest that respondents generally share similar attitudes towards leopards, regardless of the intensity of cattle predation (Fig. 2a).

\section{Discussion}

Our study revealed that almost half of the surveyed households had lost cattle to leopards within the study period, and this was one of the highest levels of human-leopard conflict across the species' range (Dar et al., 2009; Stein et al., 2010; Kabir et al., 2014). The surveyed households showed a generally non-positive attitude towards leopards and leopard 

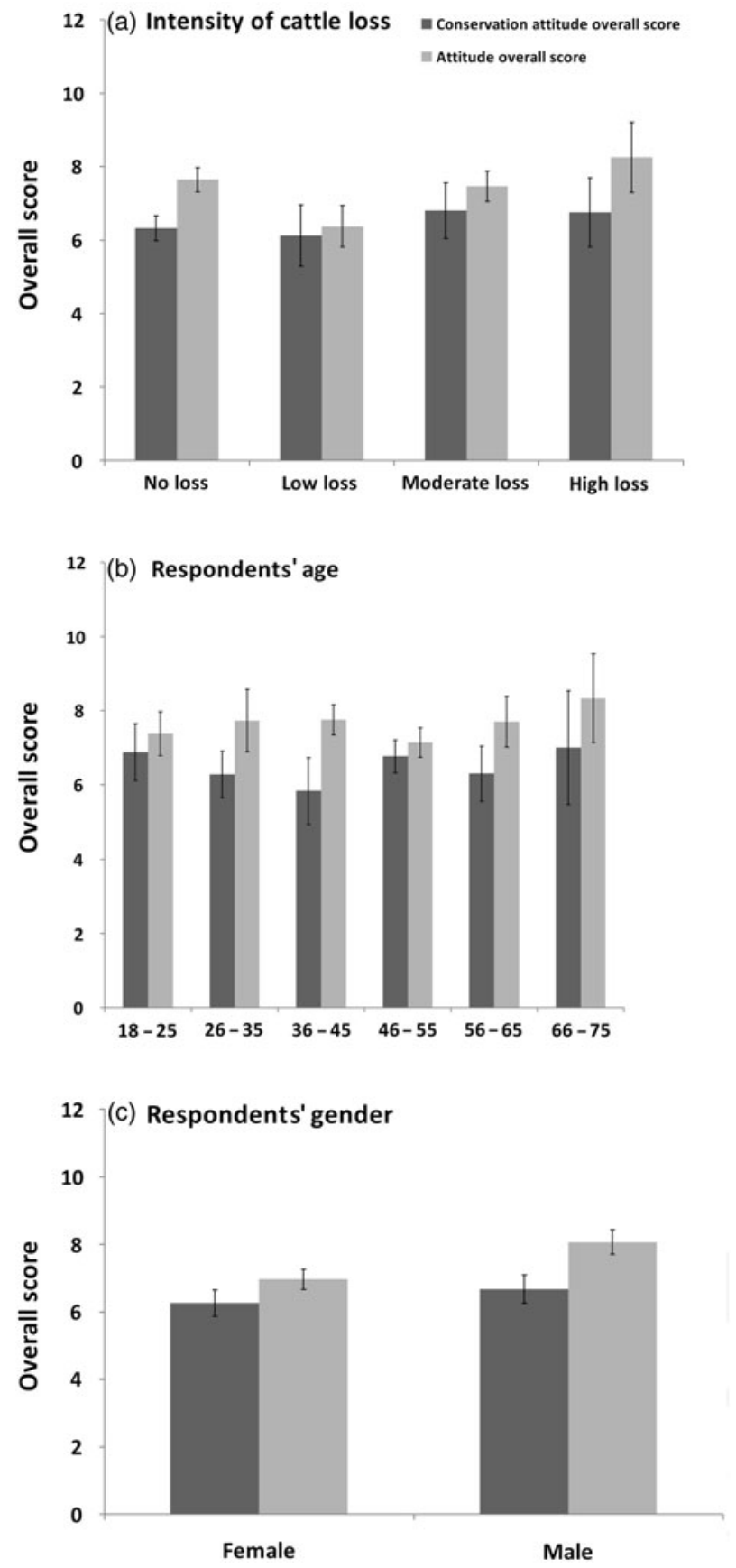

FIG. 2 Respondents' attitudes towards leopards based on: (a) intensity of cattle loss to leopards, (b) respondents' age groups, and (c) respondents' gender. Each error bar shows the mean of the variable $\pm \mathrm{SE}$.

conservation; their inaccurate understanding of leopard biology and behaviour may also contribute to their low tolerance. Raising public awareness may increase tolerance of carnivores through changing local attitudes (Zimmermann et al., 2005; Dickman et al., 2013). However, this alone would not mitigate the current level of leopard conflict in our study area because of the extremely high cost of cattle loss to villagers. Unlike situations where economic loss to livestock keepers is primarily attributed to disease and thus improved husbandry and veterinary care are prioritized (e.g. Dar et al., 2009), the high proportion of cattle loss attributed to leopards in our study area suggests that the mitigation of human-leopard conflict is a priority.

Providing economic incentives to compensate rural communities for damage caused by wildlife is among the most popular responses to mitigate human-carnivore conflict (Hemson et al., 2009; Dickman et al., 2011). Implementing a carefully designed compensation programme in parallel with close monitoring of the system has great potential for facilitating human-carnivore coexistence (Persson et al., 2015). There are two state-run financial schemes for compensating livestock breeders in Iran: (1) the livestock insurance compensation scheme offered by the Agriculture Bank of Iran and (2) wildlife conflict compensation scheme administrated through the Department of Environment. Not only were none of the respondents' cattle insured but the majority of owners were unaware of the schemes. Nonetheless, the majority of respondents were unwilling to report predator-caused cattle losses to the local wildlife authority, a prerequisite for applying for economic compensation under either of the available schemes. The main reason was that legal procedures to document these claims are too extensive and often do not lead to any financial compensation. Furthermore, respondents felt that making a claim could result in the complainant being a suspect if humancaused leopard mortality were to arise. The lack of awareness about compensation programmes, the misconceptions about the role of government and the wildlife management authority, and the long administrative process that results in delayed payments, all discourage rural livestock breeders from participating in existing compensation schemes (Loveridge et al., 2010; Rigg et al., 2011; Karanth et al., 2013). For the long-term conservation of globally iconic but locally problematic species it is critical that the strategies that are developed and implemented outweigh the local costs incurred (Dickman et al., 2013). We therefore recommend that the Department of Environment evaluates the two existing compensation schemes, in which false claiming and verification costs are considered, against well-established alternative approaches (e.g. conservation performance payments; Persson et al., 2015).

Taken in isolation, providing economic incentives might be insufficient to guarantee the co-existence of people and conflict carnivores. Our study area was characterized by very poor cattle husbandry, lacking even traditional methods such as livestock guarding by shepherds and guard dogs. Husbandry practices can significantly influence the risk of livestock predation by large carnivores (Ogada et al., 2003; Stein et al., 2010). We suggest that attentive cattle husbandry along with simple changes to existing practices have the potential to reduce leopard attacks on cattle. Accordingly, parallel to increasing the transparency of the current compensation schemes, a top priority is to develop an overall 
TABLE 2 Results of the Correspondence Analysis, with the eigenvalues and percentage of variance explained by the first three axes, and the contribution of the seven respondents' attitude variables to each of the axes.

\begin{tabular}{lccc}
\hline Character & Axis 1 & Axis 2 & Axis 3 \\
\hline Eigenvalue & 0.024 & 0.020 & 0.016 \\
\% of total variance & 28.52 & 24.12 & 19.44 \\
Contribution of the variables $^{1}$ & & & \\
For future generations & 0.9 & -23.1 & 1.9 \\
Saving unnecessary & -9.9 & -15.1 & -27.7 \\
Ecosystem role & 6.6 & 19.5 & 12.7 \\
Right of existence & 27.1 & -11.9 & -0.6 \\
Tourism incentive & 12.3 & 7.3 & -2.8 \\
Damage to livestock & -12.7 & 11.9 & 4.2 \\
Attacks on people & -19.3 & 12.4 \\
\hline
\end{tabular}

${ }^{1}$ Reflects how well each of the variables loads onto each of the axes

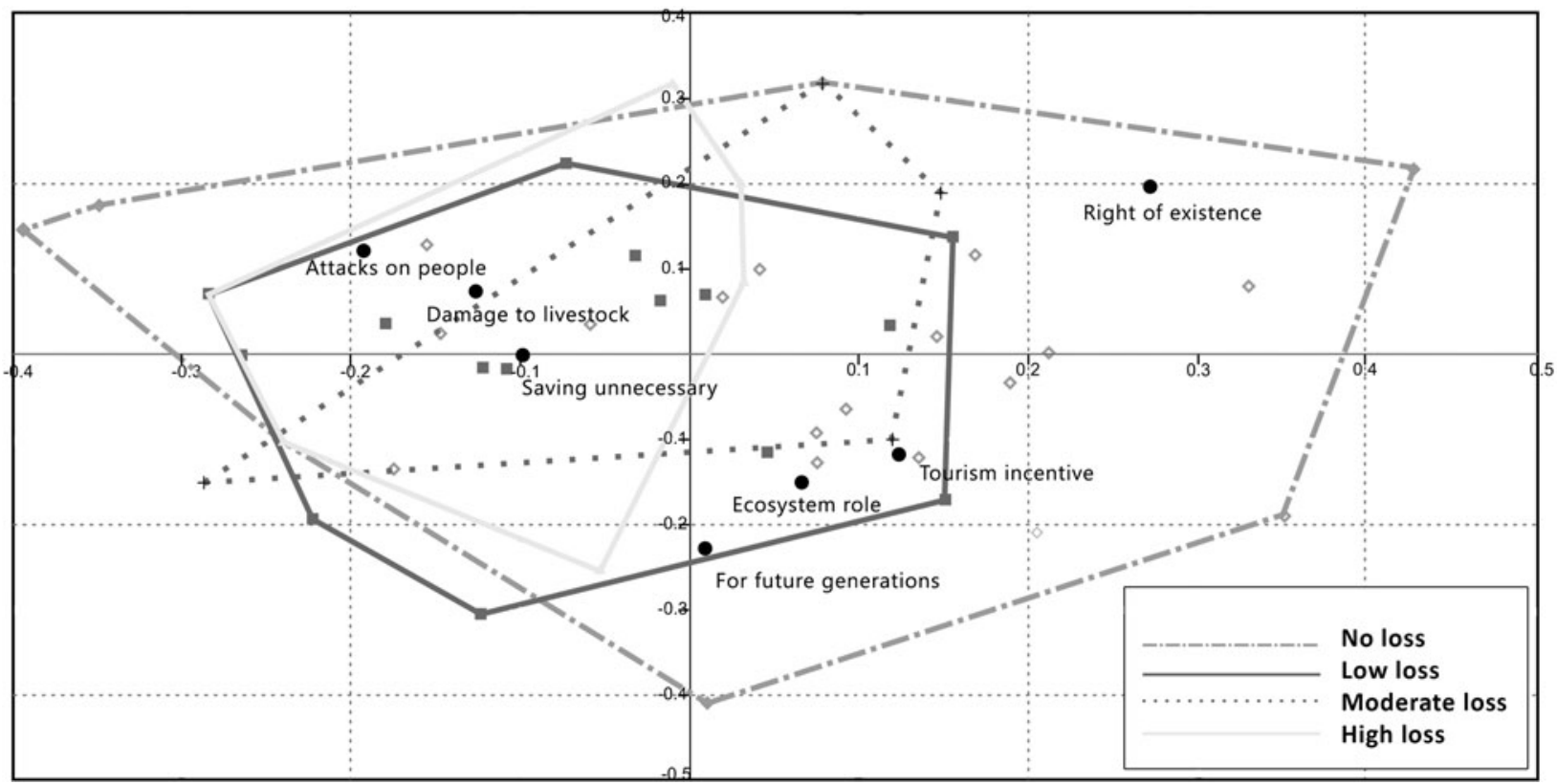

FIG. 3 A biplot from the Correspondence Analysis displaying various respondents' attitudes to leopards and how they are related to the specific groups experiencing various levels of cattle predation by the leopards (each group is shown as a convex hull). All four convex hulls show high overlap in attitudes between various respondent groups. See text for details.

comprehensive husbandry management programme with locally affordable and appropriate husbandry practices.

When appropriate management strategies are adopted, carnivores can co-exist with humans (López-Bao et al., 2015). If Iran's leopard population is to be an important resource for securing the long-term survival of the small leopard populations in the Caucasus Ecoregion (Khorozyan, 2008; Moqanaki et al., 2013) it is crucial that an understanding of human-leopard interactions will be incorporated into the current conservation initiatives, to increase local tolerance towards leopards and improve both leopard and wider conservation. Applying a combination of approaches that involve local people who have a key role in the fate of the local leopard population would be a sustainable longterm solution for leopard conservation in the humandominated habitats of the Caucasus. We have presented our results and recommendations to decision makers and local stakeholders in a detailed report of the project outcomes (see Babrgir et al., 2014, for the English version). We have focused our attention on addressing the underlying conflict using a human-leopard coexistence framework (Redpath et al., 2015). We consider that only a locally sustainable mitigation scheme in an institutionally and environmentally dynamic context would benefit all parties, notwithstanding our specific interest in conservation of the Endangered Persian leopard.

\section{Acknowledgements}

Funding for this study was generously provided by the People's Trust for Endangered Species. Gilan Provincial 
Office of the Iran Department of Environment and its branch in Siahkal are thanked for their cooperation, and S. Bagheri, S. Zavaran-Hosseini, Y. Hassan-Beigi and local wardens for assistance in the study area. We are grateful to G. Goldthorpe, L. Bahaa-el-Din, P. J. Johnson, and anonymous reviewers for helpful comments, and to P. Behnoud for his contribution in preparing Figure 3.

\section{References}

Amador-Alcalá, S., Naranjoa, E.J. \& Jiménez-Ferrera, G. (2013) Wildlife predation on livestock and poultry: implications for predator conservation in the rainforest of south-east Mexico. Oryx, 47, 243-250.

Babrgir, S., Bagheri, S. \& Soleymani, M. (2014) Capacity Building of Local Communities to Conserve the Persian Leopard in the Caucasus Eco-region. Final report to the People's Trust for Endangered Species, UK, 8o pp. Http://ptes.org/wp-content/uploads/ 2015/o1/Iran-persian-leopard-in-caucasus-eco-region-final-report.pdf [accessed 5 September 2015].

Benzecri, J.P. (1992) Correspondence Analysis Handbook. Marcel Decker, New York, USA.

Dar, N.I., Minhas, R.A., Zaman, Q. \& Linkie, M. (2009) Predicting the patterns, perceptions and causes of human-carnivore conflict in and around Machiara National Park, Pakistan. Biological Conservation, 10, 2076-2082.

Dickman, A., Macdonald, E. \& Macdonald, D. (2011) A review of financial instruments to pay for predator conservation and encourage human-carnivore coexistence. Proceedings of the National Academy of Sciences of the United States of America, 108, 13937-13944.

Dickman, A., Marchini, S. \& Manfredo, M. (2013) The human dimension in addressing conflict with large carnivores. In Key Topics in Conservation Biology 2 (eds D.W. Macdonald \& K.J. Willis), pp. 110-126. John Wiley \& Sons, Oxford, UK.

Doey, L. \& KurTA, J. (2011) Correspondence Analysis applied to psychological research. Tutorials in Quantitative Methods for Psychology, 7, 5-14.

Hammer, Ø., Harper, D.A.T. \& Ryan, P.D. (2001) PAST: paleontological statistics software package for education and data analysis. Palaeontologia Electronica, 4, 9.

Hemson, G., Maclennan, S., Mills, G., Johnson, P. \& Macdonald, D. (2009) Community, lions, livestock and money: a spatial and social analysis of attitudes to wildlife and the conservation value of tourism in a human-carnivore conflict in Botswana. Biological Conservation, 142, 2718-2725.

Kabir, M., Ghoddousi, A., Awan, M.S. \& Awan, M.N. (2014) Assessment of human-leopard conflict in Machiara National Park, Azad Jammu and Kashmir, Pakistan. European Journal of Wildlife Research, 60, 291-296.

Karanth, K.K., Gopalaswamy, A.M., Prasad, P.K. \& Dasgupta, S. (2013) Patterns of human-wildlife conflicts and compensation: insights from Western Ghats protected areas. Biological Conservation, 166, 175-185.

Khorozyan, I. (2008) Panthera pardus saxicolor. In IUCN Red List of Threatened Species v. 2015.2. Http://www.iucnredlist.org [accessed 4 September 2015].

Lescureux, N., Linnell, J.D.C., Mustafa, S., Melovski, D., Stojanov, A., Ivanov, G. et al. (2011) Fear of the unknown: local knowledge and perceptions of the Eurasian lynx Lynx lynx in western Macedonia. Oryx, 45, 600-607.
López-Bao, J.V., Kaczensky, P., Linnell, J.D., Boitani, L. \& Chapron, G. (2015) Carnivore coexistence: wilderness not required. Science, 348, 871-872.

Loveridge, A.J., Wang, S.W., Frank, L.G. \& Seidensticker, J. (2010) People and wild felids: conservation of cats and management of conflicts. In Biology and Conservation of Wild Felids (eds D.W. Macdonald \& A.J. Loveridge), pp. 161-195. Oxford University Press, Oxford, UK.

MAJiC, A. \& BATH, A.J. (2010) Changes in attitudes toward wolves in Croatia. Biological Conservation, 143, 255-260.

Mazarei, A. (1996) The Iranian economy under Islamic Republic: institutional change and macroeconomic performance (1979-1990). Cambridge Journal of Economics, 20, 289-314.

Mojtahed, A. \& Esfahani, H.S. (1989) Agricultural policy and performance in Iran: the post-revolutionary experience. World Development, 17, 839-860.

Moqanaki, E.M., Breitenmoser, U., Kiabi, B.H., Masoud, M. \& Bensch, S. (2013) Persian leopards in the Iranian Caucasus: a sinking 'source' population? Cat News, 59, 22-25.

Ogada, M.O., Oguge, N.O., Woodroffe, R. \& Frank, L.G. (2003) Limiting depredation by African carnivores: the role of livestock husbandry. Conservation Biology, 17, 1521-1530.

Persson, J., Rauset, G.R. \& Chapron, G. (2015) Paying for an endangered predator leads to population recovery. Conservation Letters, 8, 345-350.

R Development Core Team (2015) R: A Language and Environment for Statistical Computing. R Foundation for Statistical Computing, Vienna, Austria. Http://www.R-project.org [accessed 25 August 2015].

Redpath, S.R., Bhatia, S. \& Young, J. (2015) Tilting at wildlife: reconsidering human-wildlife conflict. Oryx, 49, 222-225.

Rigg, R., Findoo, S., Wechselberger, M., Gorman, M.L., SilleroZubiri, C. \& Macdonald, D.W. (2011) Mitigating carnivorelivestock conflict in Europe: lessons from Slovakia. Oryx, 45, $272-280$

Stein, A.B., Fuller, T.K., Damery, D.T., Sievert, L. \& Marker, L.L. (2010) Farm management and economic analyses of leopard conservation in north-central Namibia. Animal Conservation, 13, 419-427.

Thirgood, S., Woodroffe, R. \& Rabinowitz, A. (2005) The impact of human-wildlife conflict on human lives and livelihoods. In People and Wildlife, Conflict or Coexistence? (eds R. Woodroffe, S. Thirgood \& A. Rabinowitz), pp. 13-26. Cambridge University Press, Cambridge, UK.

Treves, A. \& Bruskotter, J.T. (2014) Tolerance for predatory wildlife. Science, 344, 476-477.

Walpole, M.J. \& Goodwin, H.J. (2001) Local attitudes towards conservation and tourism around Komodo National Park, Indonesia. Environmental Conservation, 28, 160-166.

Zimmermann, A., Walpole, M.J. \& Leader-Williams, N. (2005) Cattle ranchers' attitudes to conflicts with jaguar Panthera onca in the Pantanal of Brazil. Oryx, 39, 406-412.

\section{Biographical sketches}

SIMA BABRGIR is interested is in human-wildlife conflict mitigation and community-based conservation. Moнаmmad S. FARHADinia is a conservation biologist with an interest in the dynamic interactions between carnivores and their ecosystems, including human communities. EHSAN M. MOQANAKI's research interest is in the application of non-invasive techniques for a better understanding of the ecology and conservation of wildlife populations. 